Claire B. Rubin*

\title{
Reflections on 40 Years in the Hazards and Disasters Community
}

DOI 10.1515/jhsem-2015-0050

Abstract: This piece is based on the keynote address I delivered at the 40th Annual Conference of the Hazards Center at the University of Colorado/Boulder in July (www.colorado.edu/hazards). My charge from the Hazards Center was to "provide your reflections on how our community (researchers and practitioners) has evolved over the last four decades" and "feel free to get personal and to talk about what the community has meant to you and your work." Unlike the other keynote talks at that conference, and unlike the other articles in this journal, this is a personal history, based on my career experiences over the past 38 years. As such, it includes many candid comments on things that have gone well and things that have not over the past four decades.

Keywords: disaster community; reflections on 40 years.

\section{By Way of Introduction}

I have had a quite varied career path - as researcher, consultant, and practitioner, educator - with a lot of part-time and consulting assignments. I have worked for several government agencies, a few universities, about a dozen consulting firms, my own company, and now for a local government office of emergency management - and for at least two dozen employers. I like to think of myself as versatile rather than as someone who cannot hold a job!

But this choppy employment history does raise some fundamental questions about credentials. Considering the many jobs I have had, I am not sure if it is my fault - because I do not have a PhD and could not be a tenured member of a university research center - or if it indicates that the emergency management (EM) field could not provide steady and sustained employment opportunities. I enjoyed the great variety of projects and have had some cutting-edge assignments, but it was a hard way to make a living, and I do not recommend it!

*Corresponding author: Claire B. Rubin, President, Claire B. Rubin and Associates, LLC, Arlington, VA and cofounder of JHSEM, e-mail: cbrubin@yahoo.com 


\section{The Hazards Conference as a Focal Point}

The reason I gave the keynote talk is that I had attended more Hazard Conferences than anyone else - at least 38 or 39 of them. I see the annual workshop as a focal point. Beginning in 1975 and continuing to the present, it has been the place where knowledge has been imparted, contacts have been made, friendships have been formed, and projects have been created.

A very important factor is the people in the hazards/disaster/EM field. I consider the pantheon of capable, dedicated professionals significant to my career and truly appreciate all those who provided inspiration and guidance to me through the years. The early notables were Gilbert White (Hazards Center), Henry Quarantelli and Russell Dynes (Disaster Research Center), and Charlie Fritz (National Academy of Sciences).

Others, such as Ugo Morelli [at the Federal Disaster Assistance Administration and Federal Emergency Management Agency (FEMA)], Roy Popkin (Red Cross), and Bill Anderson [at National Science Foundation (NSF)], were important to me both as colleagues and friends. These men not only excelled as researchers, facilitators of research, or practitioners, but also were unusually willing and gracious to newcomers in the field.

More recently, many prominent women researchers have emerged - Kathleen Tierney, Joanne Nigg, Shirley Laska, and Susan Cutter, to name just a few.

For me, the value of the workshops comes from the unique emphasis on bringing the academic and practitioner groups together to learn from and work with each other. Through these opportunities, I not only formed lasting professional relationships but also made life-long friends. This center and the communities of attendees have been central to my work.

\section{My Background}

I am a social scientist with an emphasis on public administration and public policy.

My involvement with the research community began in 1977, soon after National Earthquake Hazard Reduction Program was enacted and shortly before FEMA was created (1979). (I have been in the disaster business longer than FEMA has!)

Initial contact was when Ugo Morelli and Chuck Thiel (NSF), who were working with Office of Science and Technology Policy in the Executive Office of the president, dropped by my office at the International City Management 
Association (ICMA) and asked for help in organizing workshops with local public officials regarding the implementation of National Earthquake Hazard Reduction Act. That was when I got hooked on the interaction between public officials and the scientific community with regard to hazards and disasters.

In the late 1970s, while I was working at the Academy for State and Local Government, my first major project was with the National Governors Association (NGA). The NGA was engaged in some essential research and produced several ground-breaking documents on emergency management, one of which was titled Comprehensive Emergency Management (1978). That NGA work provided a significant baseline for the newly formed FEMA.

In the late 1990s I was an adjunct faculty member with the George Washington University, and that led to my developing teaching products and educational materials (time line charts, history book), because there simply was not much out there in the way of teaching materials and I could not find what I needed. During that period, I developed the Disaster Time Line charts as a teaching tool for the students in my classes.

In later years, I developed the Terrorism Time Line, the Century Time Line, and several other time lines (all of which can be browsed at http://www.disaster-timeline.com). A key feature apparent in all these time lines is how reactive our national system of emergency management is. These and subsequent charts show the causal relationships between events and outcomes, and it becomes quite evident that major events drove changes in the national emergency management system.

Looking back, however, I see two essential elements that stand out in my career: One is the hazards/disaster community and the second is being based in Washington, DC.

\subsection{Essential Element \#1: The Hazards/Disaster/Emergency Management Community}

For many years I have participated in two annual events. The first is the Hazards Conference; the second is the Higher Education in Emergency Management Symposium, sponsored by FEMA's Emergency Management Institute and now it its 17 year. There is some overlap of attendees, but roughly characterized, the first group includes many of the major researchers and practitioners who create the intellectual content for education and training, and the second group primarily delivers education and training.

For those of us in the hazards/disaster/EM field, the Hazards Center offers two major benefits. First, it fills the role of a professional association: it offers 
an annual workshop, maintains a library, has a newsletter or two, and supports a community of people with common interests. But it does not collect dues, nor does it have committees for members to serve on! Second, it provides serendipitous connections with other attendees. For example:

- As a panelist in a session, I reported out some recent research findings on the frequency and location of presidential disaster declarations. Ann Patton, from city of Tulsa, was in the audience and learned from our data that Tulsa had the greatest number of disaster declarations in a 20-year period. She shared that data with the mayor of Tulsa, and the research report was a tipping point for city's taking action on flood mitigation.

- Plans for the history book, Emergency Management: The American Experience, 1900-2010, began in 2004 when Gerard Hoetmer, then head of the Public Entity Risk Institute (PERI), and I discussed the need for a book on the history of emergency management in the US, using the disaster time line charts as a starting point. I agreed to be the editor of such a book, which is now in its second edition and has outlived PERI by several years.

\subsection{Essential Element \#2: Washington, DC}

Living and working in the Washington DC area has provided me with the unique opportunity to interact with practitioners, particularly federal ones and their contractors, and has been the source of many grants and contracts.

Being based in Washington, DC was important to my career in that I got in on some foundational projects. Many were essential to capturing history, since do much of emergency management history was never written down.

\section{Some Specific Disaster Events and Outcomes Over the Last 40 Years}

Rather than go decade by decade, I will divide the last 40 years of hazards and disaster activities into two time segments: the last quarter of the twentieth century and the first 15 years of the twenty-first century.

In the last quarter of twentieth century, we saw the buildup of the EM field, not only in terms of personnel numbers but also in the development of plans, policies, and tools; higher education programs; and increasing professionalization.

However, in the twenty-first century, and especially since 9/11, the EM field has struggled and in some ways is stalled. New threats and hazards have 
emerged, and new federal systems, plans, and guidance are not quite ready for new challenges.

I will cite some key focusing events, some important outcomes, and examples of my peripheral involvement.

\subsection{Late Twentieth Century: Emergency Management as a New Frontier, 1975-2000}

During the last quarter of the previous century, there were six disasters that qualify as defining or focusing events:

- Hurricane Hugo (1989)

- Loma Prieta (1989)

- Exxon Valdez (1989)

- Hurricane Andrew (1992)

- Great Midwest Floods (1993)

- Northridge Earthquake (1994)

These disasters resulted in the following major organizational/professional activities or actions:

- Work of the NGA; creation and implementation of Comprehensive Emergency Management Project results

- Formation of FEMA on June 19, 1978, by executive order of the president

- Development of the Federal Response to a Catastrophic Earthquake Plan, which was the precursor to the National Response Plan and later the National Response Framework

- First ICMA “Green Book” on emergency management (1991), a seminal textbook (funded by FEMA!) that was used for about 15 years and contributed to the growth of higher education in emergency management programs

- Creation of PERI (1997) with a private endowment. Its staff of risk takers funded small projects and exerted their independence in support of worthwhile missions.

During this period, my contributions and products were as follows:

- Served as lead author of Community Recovery after a Major Disaster (1985), a monograph published by Natural Hazards Research and Applications Information Center (NHRAIC).

- Did Hurricane Hugo fieldwork with Roy Popkin, with a Quick Response grant from NHRAIC, and coauthored a Quick Response Research Report for the National Hazards Center (1989). 
- Prepared the chapter on recovery for first ICMA “Green Book" on emergency management (1991).

- Did Hurricane Andrew fieldwork (1992) for both ICMA and as part of a team at the National Academy of Public Administration (NAPA) that issued the report, Coping with Catastrophe (1993).

Regarding the NAPA report, done 12 years into FEMA's operation and about halfway through its roughly 25 years as an independent agency, it was essentially the first in-depth evaluation of the agency and was the result of serious failures by FEMA after Hurricane Andrew. The report turned out to be a very significant product, one that did in fact influence decision-makers and public policy makers. For James Lee Witt, for example, who assumed his position as FEMA director just as the report was being finished, it was instrumental in supporting his significant efforts to bolster hazard mitigation, among other things.

\section{Early Twenty-First Century: 2000-2015}

During the first 15 years of this current century, there were five disasters that qualify as defining or focusing events:

- Attacks on WTC and Pentagon (2001)

- Hurricanes Katrina/Rita/Wilma (2005)

- British Petroleum (BP) Oil Spill (2010)

- Megastorm Sandy (2012)

- Various catastrophic events worldwide, such as those in Haiti, Japan, and Nepal.

All of these events were huge and can be considered "focusing events or game changers." They set a record for each of the three types of disasters: natural, manmade accidental, and man-made intentional. Entire books have been written about each of them, and probably more will come. This is not the time to elaborate on all these events, but I would like to talk briefly about 9/11 and Hurricane Sandy.

\subsection{September 11, 2001}

Among my professional contributions during this period were some post-9/11 reports and preparation of the Terrorism Time Line (http://www.disaster-timeline.com), 
which provides a snapshot of the outpouring of laws, regulations, guidance, and organizational changes that occurred between 2001 and 2008. In less than a decade, there were

- $\quad$ Twenty-one major laws

- Thirty-six executive directives

- Thirty-eight national strategies, plans, or national-level exercises

- Fourteen other federal actions and organizational changes, including the formation of the U.S. Department of Homeland Security (DHS).

To my knowledge, it is the greatest outpouring of public policy actions to take place in US history in less than one decade.

\subsection{Hurricane Sandy}

Regarding Hurricane Sandy, although the response was dramatic, for the most part it went well. Both FEMA and the Red Cross had learned lessons from their Hurricane Katrina experience, both did a lot of advance/anticipatory planning, and both went flat out in their response efforts.

Currently, however, it is the recovery phase that is the crucial story. The recovery phase entailed dealing with massive needs and demands, given the high density and coastal exposure of New York and New Jersey. Additionally, the number of housing units and the amount of major infrastructure affected was unprecedented. And newly awakened awareness of global warming and sea level rise are highlighting the need for greater mitigation and for greater attention to resilience, which will mean an extended the time for recovery.

The unusual impacts, needs, and special demands led to new organizational arrangements after Sandy, with the president giving the lead for long-term recovery to the Department of Housing and Urban Development (HUD). A special federal task force was established by executive order, and HUD was charged with overseeing its recommendations and implementation. Moreover, this was the first use of the National Disaster Recovery Framework (issued in 2011) for a major disaster event. In short, attention was given to the new concept of resilience, which was incorporated into a situation with climate change, sea level rise, and the need for a longer horizon given to mitigation and recovery.

Many new organizational arrangements were put in place to deal with the recovery process after Sandy. It remains to be seen if the task force and new roles for HUD are employed again for future disasters. 


\subsection{The Past 15 Years in General}

During this period, my contributions and products were as follows:

- Cofounder of the Journal of Homeland Security and Emergency Management (2003) to help foster an understanding of how emergency management and homeland security would be related and interact

- Continued development of time lines (Disaster Time Line, Homeland Security Time Line, California Earthquake Time Line, Mine Safety Time Line, and the Canadian Time Line)

- Editor of the first edition of Emergency Management: The American Experience (2007). (The second edition came out in 2012).

\section{The Last 40 Years: What Worked and What Didn't}

Once again, rather than go decade by decade, I will assess the last 40 years of hazards and disaster activities in two time segments: the twentieth century and the twenty-first century.

\subsection{The Twentieth Century}

In the last century, civil defense lessened as the focus, while natural and manmade hazards and disasters increased. This led to the development of a modern civil emergency management system. Laws were passed, regulations developed, doctrine written, and policies implemented by federal agencies with emergency management responsibilities under the laws and regulations.

The states and local governments looked to Washington DC for guidance, information, and inspiration. So did other countries around the world. Although FEMA gets the most attention, emergency management activities also involved numerous other agencies, such as the Environmental Protection Agency and the National Oceanographic and Atmospheric Administration. For FEMA, however, as well as for the health and welfare of the EM field, there were peaks and troughs. The Giuffrida era (1981-1985) appears to have been the low point, and the James Lee Witt administration (1993-2001) the high point. From 2001 on, FEMA initiated the national-level frameworks.

The federal government has made a few attempts at collecting and sharing "lessons learned" nationwide, but it has never quite succeeded. The most recent 
effort, the Lessons Learned Information Sharing program (LLIS.gov), failed in 2014.

In the research community, the field was small, and everyone knew the right people to call for help and information. There were fewer academic research centers. The Natural Hazards Center was formed and joined the Disaster Research Center (already 10 years old) to help grow the field. Both were oriented to social science.

Colleges and universities throughout the country started to offer certificates and advanced degrees in emergency management.

\subsection{The Twenty-First Century}

In the current century, EM has become an ever-changing field, with new and more complex and compound threats and hazards. Events are covering everwider areas and need billions of dollars for recovery. Meanwhile, the population is growing and moving to the most vulnerable geographic areas. Hence, there is an increasingly greater need for frequent updates in enabling legislation, guidance, programs, and education and training. In short, more capability and more money are needed: easier said than done!

In fact, there is no shortage of rules, regulations, guidance, doctrine, and requirements, but this plethora of dictates is increasing while the budgets and staff for EM personnel at the state and local levels are static or decreasing. This does not bode well for the future of public sector emergency management.

\subsubsection{FEMA and the Federal Government}

Currently, there are major issues with several types of workers - primarily, full-time employees, FEMA reservists, and FEMA Corps. Low morale plagues the DHS fulltime staff as a whole. The FEMA Reservist system has been revamped, and many in it are unhappy with new rules and requirements. Use of FEMA Corps personnel with "lightly" trained young adults is increasing in order to save money. At a time of bigger, more complex disasters, the workforce has become more complex. ${ }^{1}$

Reliance on FEMA as a reliable partner in EM - and on federal funding support in general - has decreased. In fact, in 2014 the head of the Brookings

1 For details, see Government Accountability Office, Federal Emergency Management Agency: Additional Planning and Data Collection Could Help Improve Workforce Management Efforts, GAO15-437 (Washington, DC, July 2015), http://www.gao.gov/assets/680/671276.pdf. 
Institute delivered an op-ed piece on "How Washington Made Itself Irrelevant." Among the key reasons are congressional actions (or lack thereof) on budgets; sequestration; and threats of department shut downs.

In the research community, the gap between academics, researchers, and practitioners has widened in the wake of more academic research centers, more federal agencies, more personnel, and more consultants, especially at DHS. In particular, the number of intermediaries between researchers and practitioners has grown. In the old days, we often knew who was researching what and could call on them; today, this is out of the question.

DHS created numerous university-based "Centers of Excellence" to focus on single issues, such as terrorism and coastal hazards. I consider these large amalgamations of universities to be "research oligarchies," and the costs/benefits of supporting research in this way do not make sense. Researchers cannot easily access key officials - whether to discuss potential research projects or to obtain guidance on issues.

The federal government is not really flexible and agile, not secure in its funding for more than 1 year at a time, and always struggling to catch up. We cannot count on it to get out ahead of some of our current threats, let alone future hazards and threats in this political environment. Among the areas lagging are mitigation and recovery.

Yet there are two areas of positive change. First, despite the rise of climate change deniers, including members of Congress and governors of disaster-prone states, there have been tremendous improvements in science and technology. Second, the growth of the Internet and the advent of social media have greatly enhanced communications. Both responders and victims have benefited in many ways.

\subsubsection{Hazards/Disaster Science, Public Policy, and Education}

There has been an increase in training and formal education within the EM community. We now have more than 250 institutions of higher education offering courses in EM and homeland security. Many more books and other educational materials have become available in past 20 years. Yet, for many reasons, disaster science is not being applied by those who make policy and program decisions. A

2 Bruce Katz, "How Washington Made Itself Irrelevant,” Washington Post, December 4, 2014, http://www.washingtonpost.com/opinions/how-washington-made-itself-irrelevant/2014/12/04/ d1a1fec0-74c2-11e4-9d9b-86d397daad27_story.html (Katz 2014). 
recent, editorial in Science magazine regarding disaster science centers and policy makers commented on this widening gap between knowledge creators and public policy makers. ${ }^{3}$ So while we have seen an increase in knowledge about many aspects of hazards/disasters and emergency management, growth in knowledge does not necessarily result in growth in competence and effectiveness. ${ }^{4}$

\subsubsection{The State of Long-Term Recovery}

There has been relatively little progress on Long-Term Recovery. Since the 1985 recovery monograph for which I was the lead author, ${ }^{5}$ I have been quite disappointed in the failure of FEMA to develop an empirical knowledge base, develop models, and improve understanding and capacity to do long-term recovery. And I think FEMA should have employed NAPA or the National Academy of Sciences to assist with its Recovery Framework efforts.

\subsubsection{Funds and Flexibility}

We need more nonfederal and flexible sources of funding available quickly for worthwhile projects. We need a new version of PERI - a privately funded, independent organization that will quickly and easily provide small grants for innovative projects proposed by researchers or single organizations. We need more private, nonprofit organizations. The Bill Anderson Fund is an excellent example of a private, nonprofit organization that supports researchers and applied research projects while furthering the inclusion of minorities in the EM field.

\section{Closing Thought}

Like all endeavors, our field has enjoyed a steady progression. There have been many lurches forward as well as backward. "Punctuated equilibrium" is the term public administration researchers have used.

3 Marcia McNutt, "Editorial: A Community for Disaster Science,” Science, April 2, 2015, p. 11.

4 See, for example, the excellent presentation by Susan Cutter, "Natural Hazards: Why More Knowledge Is Not Reducing Losses,” from her Gilbert White Memorial Lecture, December 4, 2014, available at http://dels.nas.edu/global/besr/GW-Lecture.

5 Claire B. Rubin, with Martin Saperstein and Daniel G. Barbee, Community Recovery after a Major Natural Disaster, Monograph \#41 (Boulder, Colo.: Hazards Research Center, 1985), http:// scholarcommons.usf.edu/cgi/viewcontent.cgi?article=1086\&context=fmhi_pub. 
In the coming years, we will face new threats and hazards, along with advances in technology and science. We will have a vastly wider range of choices and tools, but also a comparably large number of risks and responsibilities.

Are we up to the challenge?

\section{References}

Cutter, Susan (2014) “Natural Hazards: Why More Knowledge Is Not Reducing Losses." Lecture presented at the Gilbert F. White Lecture Series, Washington, DC, December 4, 2014, Available at: http://dels.nas.edu/global/besr/GW-Lecture.

Federal Emergency Management Agency (FEMA) (2015) “Former Administrators." Last updated January 31, 2015, Available at: https://www.fema.gov/former-administrators.

Government Accountability Office (GAO) (2015) Federal Emergency Management Agency: Additional Planning and Data Collection Could Help Improve Workforce Management Efforts, GAO-15-437. Washington, DC, July 2015, Available at: http://www.gao.gov/ assets/680/671276.pdf.

Katz, Bruce. (2014) How Washington Made Itself Irrelevant. Washington Post, December 4, 2014, Available at: http://www.washingtonpost.com/opinions/how-washington-madeitself-irrelevant/2014/12/04/d1a1fec0-74c2-11e4-9d9b-86d397daad27_story.html.

National Governors Association (NGA) (1978) Comprehensive Emergency Management Project. Washington, DC: NGA, (out of print).

Rubin, Claire B., ed. (2012) Emergency Management: The American Experience, 1900-2010. 2nd ed. Boca Raton, FL: CRC Press.

Rubin, Claire B., with Martin Saperstein and Daniel G. Barbee (1985) Community Recovery after a Major Natural Disaster. Monograph \#41. Boulder, CO: Hazards Research Center, Available at: http://scholarcommons.usf.edu/cgi/viewcontent.cgi?article=1086\&context=fmhi_pub.

Article note: This paper is derived from the Keynote Talk given at the 40th Annual Conference of the Natural Hazards Center of the University of Colorado/Boulder, Brookfield, CO, July 21, 2015. The slide set prepared for this talk is on the http://www.RecoveryDiva.com website, posting dated October 25, 2015. 